Provided for non-commercial research and education use. Not for reproduction, distribution or commercial use.

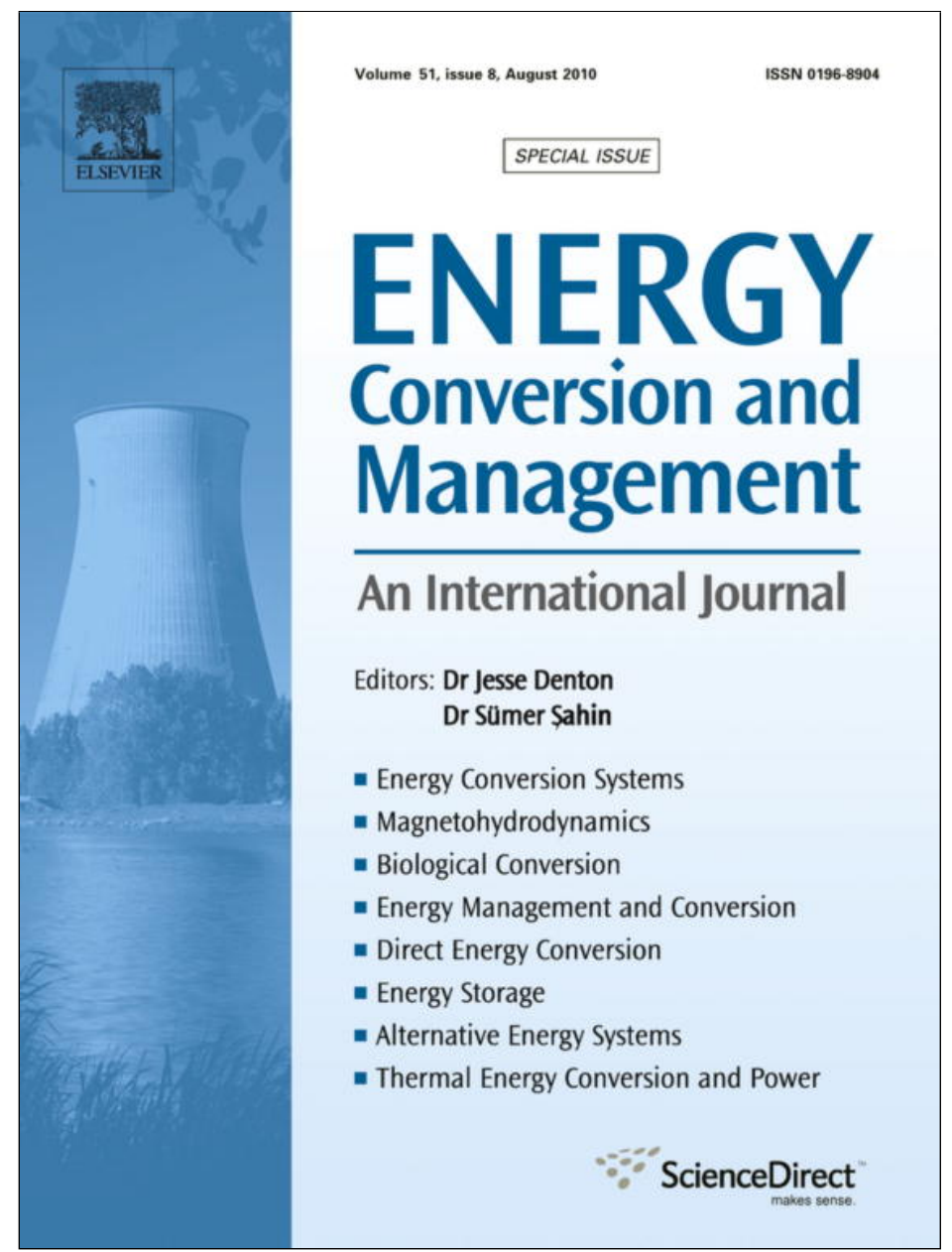

This article appeared in a journal published by Elsevier. The attached copy is furnished to the author for internal non-commercial research and education use, including for instruction at the authors institution and sharing with colleagues.

Other uses, including reproduction and distribution, or selling or licensing copies, or posting to personal, institutional or third party websites are prohibited.

In most cases authors are permitted to post their version of the article (e.g. in Word or Tex form) to their personal website or institutional repository. Authors requiring further information regarding Elsevier's archiving and manuscript policies are encouraged to visit:

http://www.elsevier.com/copyright 


\title{
Development of high-performance solar LED lighting system
}

\author{
B.J. Huang *, M.S. Wu, P.C. Hsu, J.W. Chen, K.Y. Chen \\ New Energy Center, Department of Mechanical Engineering, National Taiwan University, Taipei, Taiwan
}

\section{A R T I C L E I N F O}

\section{Article history:}

Available online 28 December 2009

\section{Keywords:}

Stand-alone solar system

Off-grid solar system

Solar-powered lighting

LED lighting

Solar LED lighting

\begin{abstract}
A B S T R A C T
The present study developed a high-performance charge/discharge controller for stand-alone solar LED lighting system by incorporating an nMPPO system design, a PWM battery charge control, and a PWM battery discharge control to directly drive the LED. The MPPT controller can then be removed from the stand-alone solar system and the charged capacity of the battery increases $9.7 \%$. For LED driven by PWM current directly from battery, a reliability test for the light decay of LED lamps was performed continuously for $13,200 \mathrm{~h}$. It has shown that the light decay of PWM-driven LED is the same as that of constant-current driven LED. The switching energy loss of the MOSFET in the PWM battery discharge control is less than $1 \%$. Three solar-powered LED lighting systems ( $18 \mathrm{~W}, 100 \mathrm{~W}$ and $150 \mathrm{~W}$ LED) were designed and built. The long-term outdoor field test results have shown that the system performance is satisfactory with the control system developed in the present study. The loss of load probability for the $18 \mathrm{~W}$ solar LED system is $14.1 \%$ in winter and zero in summer. For the $100 \mathrm{~W}$ solar LED system, the loss of load probability is $3.6 \%$ in spring.
\end{abstract}

(c) 2009 Elsevier Ltd. All rights reserved.

\section{Introduction}

Stand-alone-solar-powered system is widely used in remote areas where the grid power cannot reach. Therefore, durability and reliability are the two key issues. The system has to be designed with a good matching between the installed capacity of solar photovoltaic module and battery capacity, according to a specific energy load in order to obtain a proper loss of load probability (LLP) in long-term performance [1]. A good charge/discharge control technique is thus needed.

For lighting application using light-emitting diode (LED), the load is employed at night which is not in phase with power generation at daytime. To assure good performance, three important factors have to be considered: (1) high efficiency in photovoltaic (PV) power generation; (2) good battery charge control to charge the battery in full capacity to provide enough energy storage and protect the battery from overcharge; (3) good battery discharge control for lighting without damaging the LED and provide a sufficient illumination at night.

In the present study, we adopt a near-maximum-power-pointoperation (nMPPO) design of photovoltaic power generation system [4] to get rid of a maximum-power-point-tracking controller (MPPT) by properly matching the PV module specification with the battery voltage in design to obtain a similar performance of MPPT. The additional cost, reliability problem, and energy loss of the MPPT is thus avoided.

\footnotetext{
* Corresponding author. Tel.: +886 23634790; fax: +886223640549.

E-mail address: bjhuang@seed.net.tw (B.J. Huang).
}

To charge the battery in full capacity, a battery charge control system using pulse-width modulation (PWM) technique and feedback control is developed in the present study.

To eliminate the DC/DC conversion loss of battery discharge, the LED is directly driven by the battery voltage using a PWM technique with constant-power feedback control.

The present study integrates the above three kinds of unique techniques to develop a high-performance stand-alone solar LED lighting system.

\section{Development of battery charge control system}

\subsection{Design of $n M P P O$ for $P V$ power generation}

A flat-plate PV module with $2 \mathrm{X}$ reflective-type concentrator (Fig. 1) was used in the present study. Huang and Sun [6] have shown the low concentration ratio reflector can increase about $23 \% \mathrm{PV}$ power generation compared to the flat-plate PV.

In grid-connected or stand-alone solar PV power generation system, a maximum-power-point-tracking controller (MPPT) is usually used to track the operating point of the PV module near its maximum-power-point $[2,3]$. For the stand-alone PV system, the system design matching between the battery, PV module, and the load becomes much more complicated. It usually needs to add a sophisticated energy management system to properly control the operation of the three components during charging and discharging phases according to the load variation to keep the MPPT performance stable. 


\begin{tabular}{|c|c|c|c|}
\hline \multicolumn{4}{|c|}{ Nomenclature } \\
\hline$P_{V}(s)$ & dynamics model of the PV & $I_{F}$ & current of LM338 output, A \\
\hline$R_{B}(s)$ & dynamics model of the battery & $V_{I}$ & voltage of the $0.01 \Omega$ resistor, $\mathrm{V}$ \\
\hline$C(s)$ & dynamics model of the controller & $V_{a}$ & voltage of the LM338 output, V \\
\hline$S_{o}$ & solar radiation intensity, $\mathrm{W} / \mathrm{m}^{2}$ & $V_{b}$ & voltage between $4 \Omega$ resistor and the MOSFET, $V$ \\
\hline$I_{P V}$ & PV current, A & $V_{i n}$ & input voltage, $\mathrm{V}$ \\
\hline$D_{\text {uty }}$ & duty-cycle of the PWM in charge control system & $I_{\text {peak }}$ & maximum current, $\mathrm{A}$ \\
\hline$e$ & control error & $P_{i n}$ & input power, $\mathrm{W}$ \\
\hline$V_{o}$ & overcharge voltage of controller, $\mathrm{V}$ & $P_{\text {out }}$ & output power, W \\
\hline$V_{B}$ & output voltage of battery, $\mathrm{V}$ & $D$ & duty-cycle in the PWM energy loss test \\
\hline$V_{O C}$ & open-circuit voltage, $\mathrm{V}$ & $I_{B}$ & output current of the battery, A \\
\hline$I_{S C}$ & short circuit current, A & $I_{\text {ave }}$ & average current, $\mathrm{A}$ \\
\hline$P_{\text {MAX }}$ & power at MPP, W & $I_{o}$ & current setting, A \\
\hline$V_{P M}$ & voltage at MPP, V & & \\
\hline & current at MPP, A & & \\
\hline
\end{tabular}

The use of MPPT increases the system cost and decrease the reliability. Huang et at. [4] developed a near-maximum-powerpoint-operation (nMPPO) design of photovoltaic power generation system that does not use a MPPT but just properly matching the PV module specification with the battery voltage in design to obtain a similar performance of MPPT. Fig. 2 shows the power generation of the PV module at ambient temperature $26 \pm 3{ }^{\circ} \mathrm{C}$. The area between the two dash lines depicts the operation voltage range of the leadacid battery which is widely used for solar LED lighting system [5] and it shows that the battery will operate near the MPP of the PV since the PV cell temperature is around $50^{\circ} \mathrm{C}$. Therefore, the system adopts the nMPPO design instead using the MPPT controller.

\subsection{Battery charge control system}

The battery charge control of a stand-alone PV system is another important issue. Usually, the battery is charged only at about $80 \%$ state-of-charge (SOC) in order to avoid over-charging. The

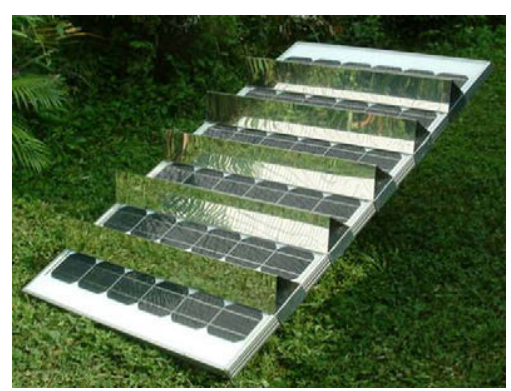

Fig. 1. Solar PV module used.

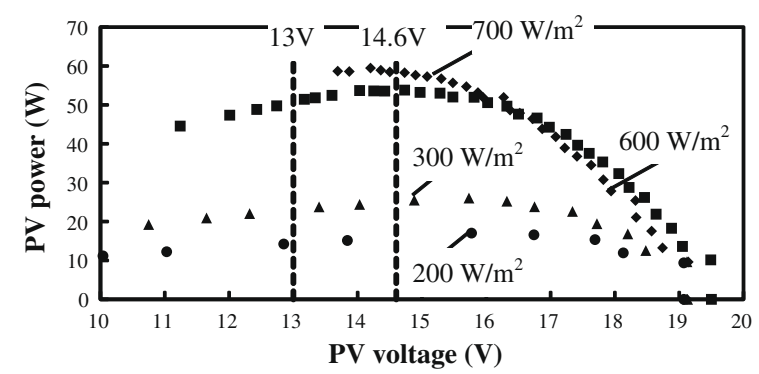

Fig. 2. Power generation of the PV module. storage capacity as well as the system performance is thus reduced.

In the present study, we use the lead-acid battery as the storage device. The battery storage capacity or lifetime can decrease rapidly due to over-charging. The way to protect battery from overcharge is to reduce the charge current when the battery voltage reaches the overcharge point.

In the present study, a feedback control system has been developed with a PWM technique to reduce the charging current and maintain the battery voltage after overcharge point $V_{o}$, as shown in Fig. 3. A metal-oxide-semiconductor field-effect transistor (MOSFET) is used to switch on/off of the charging current from solar PV by PWM technique. The mean charge current can be reduced by decreasing the duty-cycle $D_{u t y}$. The controller can be implemented in a micro-processor to feedback the battery voltage and generate the PWM signal to trigger the MOSFET. Therefore, the battery voltage can be maintained at the overcharge point by controlling the mean charge current.

\subsection{Outdoor battery charge test}

An outdoor test was then performed to test the real battery charge operation. An $85 \mathrm{Wp}$ flat-plate PV module (Table 1) with $2 \mathrm{X}$ reflective-type concentrator and a YUASA NP 38-12 (38 A h, $12 \mathrm{~V}$ ) lead-acid battery [11] were used to test the controller performance. Fig. 4 shows the daily outdoor performance test of the charge control system. The sampling interval is at $5 \mathrm{~min}$. The battery voltage setting was $14 \mathrm{~V}$. The test results show that the battery voltage never exceeds $14.1 \mathrm{~V}$ (less than the worst-case maximum voltage $14.4 \mathrm{~V}$ ). This indicates that the control system can protect the battery from overcharge.

After the overcharge point, the charge current is reduced automatically till $100 \%$ SOC. The charged energy at battery voltage up to

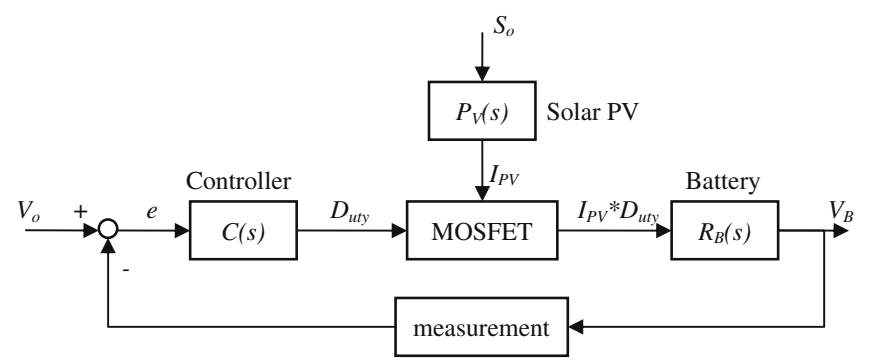

Fig. 3. Battery charging control system. 
Table 1

Specification of $85 \mathrm{Wp} \mathrm{PV}$ module under $1000 \mathrm{~W} / \mathrm{m}^{2}$ irradiation and $25^{\circ} \mathrm{C}$ module temperature.

\begin{tabular}{lc}
\hline Module name & F-MSN-85W-R02 \\
\hline Open-circuit voltage, $V_{O C}$ & $21.34 \mathrm{~V}$ \\
Short circuit current, $I_{S C}$ & $5.697 \mathrm{~A}$ \\
MPP power, $P_{M A X}$ & $81.7 \mathrm{Wp}$ \\
MPP voltage, $V_{P M}$ & $16.43 \mathrm{~V}$ \\
MPP current, $I_{P M}$ & $4.99 \mathrm{~A}$ \\
\hline
\end{tabular}

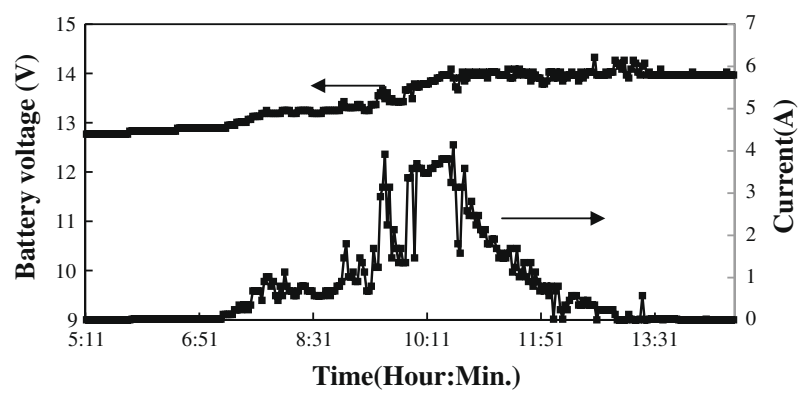

Fig. 4. Outdoor performance test of the charge control (2008/06/28).

$14 \mathrm{~V}$ is $59.6 \mathrm{~W} \mathrm{~h}$. The present charge control system can keep the battery voltage at $14 \mathrm{~V}$ and continue charging $46.6 \mathrm{~W}$ h more, after the overcharge point. In terms of $\mathrm{A} h$, the nominal charge capacity is $4.4 \mathrm{~A} \mathrm{~h}$ at battery voltage below $14 \mathrm{~V}$ and $3.3 \mathrm{Ah}$ more was charged after $14 \mathrm{~V}$. The battery life time can be influenced by the depth of discharge (DOD) [9]. A $10 \%$ reduction in nominal charge capacity is necessary for ensuring the battery life time. Therefore, the improved charge capacity by the battery charging control system according to Fig. 3 can be determined as the increased charge capacity $(3.3 \mathrm{~A} \mathrm{~h}$ ) divided by the useful battery capacity (38 A h times $90 \%$ ) which comes up to be $9.7 \%$ more charging after the overcharge point.

\section{Development of discharge control system for LED lighting}

A stand-alone solar-powered LED lighting system generates electrical power which is stored in battery and discharged at night to light the LED. The energy is produced and consumed locally. It can save the costs of grid-power transmission, including local transformers, power line material, and transmission energy loss. It has been shown that the stand-alone solar lighting system utilizing LED can save energy with reasonable payback time in remote area [7]. The use of LED as light source has another advantage of DC-powered characteristics. It seems that LED can be directly driven by the battery used in a stand-alone solar PV system. However, there is a problem in driving the LED directly from the battery. The LED is sensitive to the driving voltage as shown in Fig. 5 and the

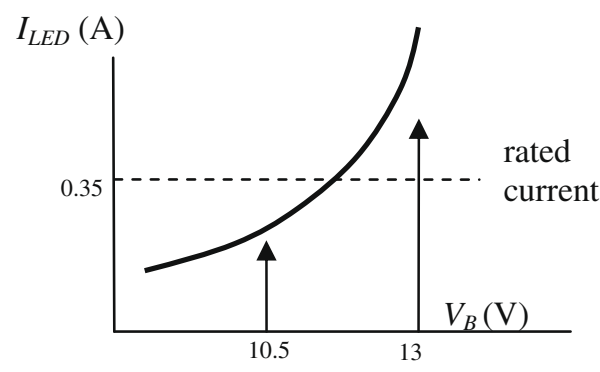

Fig. 5. $I-V$ curve of LED. battery voltage will change at different state of charge depending on solar irradiation.

A lead-acid battery usually operates at between $10.5 \mathrm{~V}$ and $13 \mathrm{~V}$ with SOC from $0 \%$ to $100 \%$ respectively. The $I-V$ curve of a LED shown in Fig. 5 indicates that the LED will be easily over driven and damaged. Therefore, the stand-alone solar LED lighting system usually consists of a DC/DC converter to convert the floating battery voltage into a constant current to drive the LED. A energy loss of the DC/DC converter, about $15 \%$, will then be introduced. The DC/DC converter may also increase the system cost and reduce the system reliability due to additional components.

The LED can be driven by pulse-width modulation (PWM) technique to maintain an average current below its rated value (e.g. $350 \mathrm{~mA}$ ). The present study develops such a technology for LED lighting directly driven by battery voltage (see Fig. 6 ).

\subsection{Reliability test of PWM-driven LED}

Some research has shown that the LED lamps can take instantaneous high current stress [8-10]. It is still not clear whether LED can be driven by PWM without causing fast light decay. A longterm reliability test for LED lamps was performed to clarify this.

A light decay test for LED lamps using constant current and different PWM current driving was carried out. Fig. 7 is the test chamber for light decay test of LED lamps. Twelve LED lamps are soldered on an aluminium PCB to maintain at the same temperature. The LED lamps are soldered in four parallel rows with three lamps of the same kind LED at each row. The chamber inside temperature is controlled at $40 \pm 3{ }^{\circ} \mathrm{C}$ using two $100 \mathrm{~W}$ tungsten bulbs and an on/off controller. A photo sensor (S2387) is used to measure the illumination of LED lamps regularly. Besides, a controller was designed using micro-processor to control the on/off of the different circuits connecting LED lamps and measure the output of the photo sensor.

A LED driver is designed to simultaneously supply four different power inputs to four rows of LED lamps:

(a) $350 \mathrm{~mA}$ constant current (the rated current) as the baseline of the LED lamps life test.

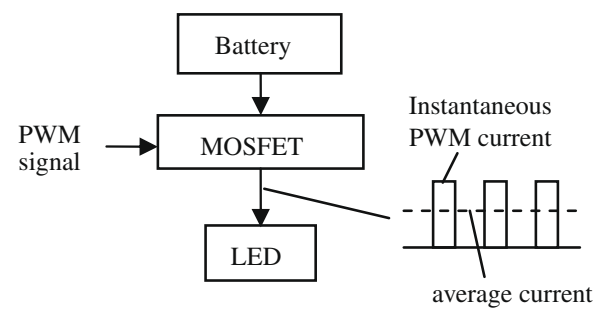

Fig. 6. LED driven by PWM technique.

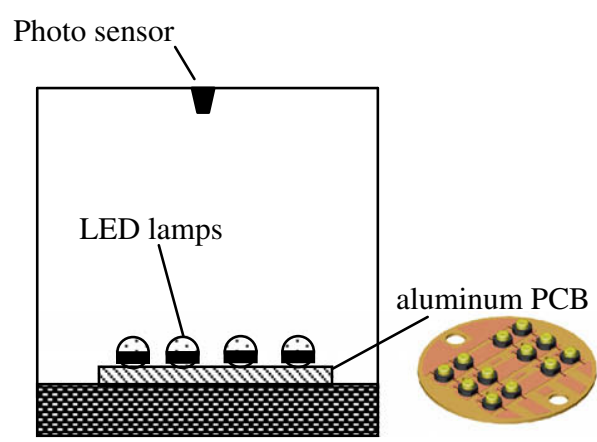

Fig. 7. Test chamber for light decay test of LED lamps. 
(b) $700 \mathrm{~mA}$, Duty-Cycle $=50 \%$, PWM-Frequency $=100 \mathrm{~Hz}$. The average current is $350 \mathrm{~mA}$ and the current stress is two times greater than Case (a).

(c) $700 \mathrm{~mA}$, Duty-Cycle $=50 \%$, PWM-Frequency $=10 \mathrm{kHz}$. The average current is $350 \mathrm{~mA}$ and the current stress is two times of Case (a) but the PWM-Frequency is 100 times greater than (b). This test intends to study the effect of frequency and the pulse stress.

(d) $1050 \mathrm{~mA}$, Duty-Cycle $=33 \%$, PWM-Frequency $=100 \mathrm{~Hz}$. The average current is $350 \mathrm{~mA}$ but the current stress is three times of Case (a).

For battery operating at $10.5-13 \mathrm{~V}$, the corresponding duty-cycle of the PWM driver is between $40 \%$ and $100 \%$ which can be provided by the above PWM driver designs. The tests were performed simultaneously to compare the light decay with different driving currents. The LED luminaire is put in the test chamber kept at $40 \pm 3^{\circ} \mathrm{C}$ to accelerate the light decay of the LED lamps. The PCB temperature is monitored and used to determine the LED junction temperature. The test has been continuously run for more than 15,800 h. Fig. 8 is the test results. It is seen from Fig. 8 that the LED junction temperature are kept at $70 \pm 3{ }^{\circ} \mathrm{C}$, except for a few test points at lower temperature due to the failure of the tungsten bulbs in chamber temperature control. It is seen that the light decay for four kinds of driving methods is not distinguishable, within experimental error. This implies that the direct driving by battery using PWM technique will not damage the LED lamps.

\subsection{Energy loss of PWM-driven LED}

The PWM driver to drive LED directly from the battery uses a MOSFET triggered by a PWM signal from a micro-processor. The DC/DC converter that is usually used in stand-alone system is omitted. However, there is energy loss in MOSFET and it needs to be determined.

We used a digital oscilloscope Tektronix TDS2014B to measure the wave form of the voltage and current across the MOSFET. An ABM 9306 DUAL-TRACKING power supply was used to provide the energy input to MOSFET. A $100 \mathrm{~W} 4 \Omega$ adjustable resistor was select as the load to simulate a $100 \mathrm{~W}$ LED luminaire. A $0.01 \Omega$ resistor is connected in series to the $100 \mathrm{~W} 4 \Omega$ resistor to measure the instantaneous current by the Ohm's law (Fig. 9). The TDS2014B measuring the $V_{a}, V_{b}$ and $V_{I}$. The current $I_{F}$ can be calculated by the $V_{I}$ and Ohm's law. The input power $P_{\text {in }}$ is $V_{a} \cdot I_{F}$ and the load power $P_{\text {out }}$ can be calculated by $\left(V_{a}-V_{b}\right) I_{F}$.

The energy loss was tested at three different PWM driving wave forms described previously. The PWM frequency is set at $125 \mathrm{~Hz}$. Figs. 10 and 11 show test results at $V_{\text {in }}=5.5 \mathrm{~V}, I_{\text {peak }}=4 \mathrm{~A}$, Duty-Cycle $D=60 \%$ and $V_{\text {in }}=24.2 \mathrm{~V}, I_{\text {peak }}=8.1 \mathrm{~A}$, Duty-Cycle $D=40 \%$. Table 2 shows that the energy loss in MOSFET at Duty-Cycle 40$80 \%$ is less than $1 \%$. This is less than the energy loss of a DC/DC con-

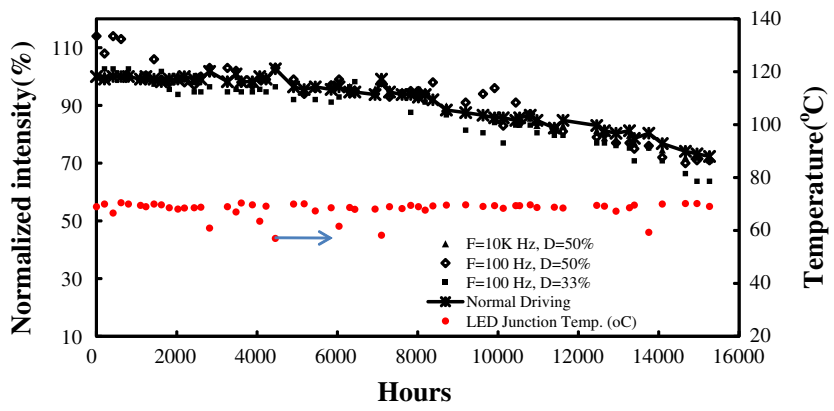

Fig. 8. LED reliability test results.

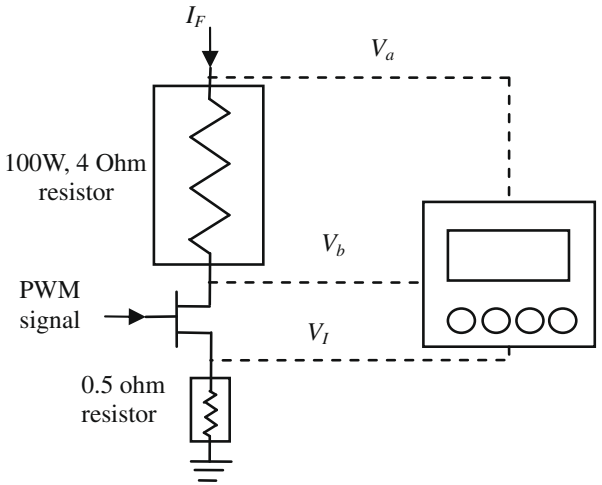

Fig. 9. Measuring device for energy loss of MOSFET.

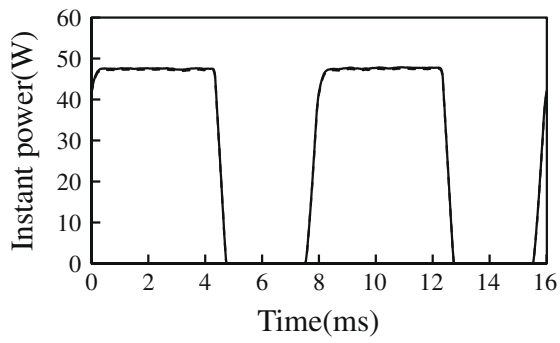

Fig. 10. Energy loss test of MOSFET at $D=60 \%\left(V_{\text {in }}=5.5 \mathrm{~V}, I_{\text {peak }}=4 \mathrm{~A}\right)$.

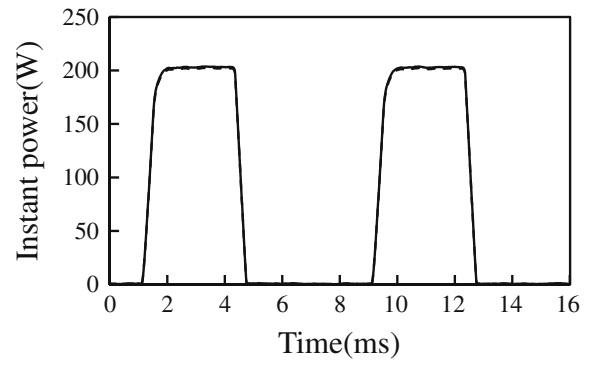

Fig. 11. Energy loss test of MOSFET at $D=40 \%\left(V_{\text {in }}=24.2 \mathrm{~V}, I_{\text {peak }}=8.1 \mathrm{~A}\right)$.

Table 2

Energy loss of MOSFET in PWM at $125 \mathrm{~Hz}$.

\begin{tabular}{lllrrll}
\hline$I_{\text {peak }}(\mathrm{A})$ & Duty-Cycle $(\%)$ & $V_{a}(\mathrm{~V})$ & $P_{\text {in }}(\mathrm{W})$ & $P_{\text {out }}(\mathrm{W})$ & Loss $(\mathrm{W})$ & Loss $(\%)$ \\
\hline 4 & 100 & 11.8 & 47 & 46.9 & 0.1 & 0.2 \\
4 & 80 & 11.8 & 37.6 & 37.4 & 0.25 & 0.65 \\
4 & 60 & 11.8 & 28.1 & 27.9 & 0.19 & 0.67 \\
4 & 40 & 11.8 & 18.6 & 18.5 & 0.13 & 0.69 \\
8.1 & 100 & 24.2 & 196.3 & 196.2 & 0.08 & 0.04 \\
8.1 & 80 & 24.2 & 157.3 & 156.3 & 1 & 0.64 \\
8.1 & 60 & 24.2 & 117.5 & 116.7 & 0.76 & 0.65 \\
8.1 & 40 & 24.2 & 80.2 & 79.6 & 0.56 & 0.7 \\
\hline
\end{tabular}

verter. The energy loss of MOSFET can be further reduced by using a better MOSFET and new circuit design.

\subsection{Discharge control system for LED}

The discharge control system for LED lighting is shown in Fig. 12. The controller is implemented in a micro-processor to output a PWM signal to trigger the MOSFET to deliver a PWM current to LED for lighting. The PWM current is measured and analyzed to 


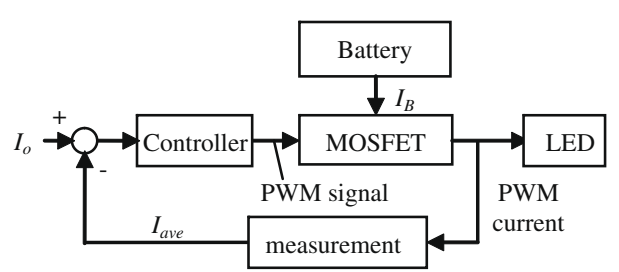

Fig. 12. Discharge control system for LED lighting.

determine the average current $I_{\text {ave }}$ for feedback control according to the setting value $I_{o}$.

\subsection{Design of central control system}

The central control system can be realized by using a microprocessor (PIC18F252). Fig. 13 shows the algorithm of the central control system. Fig. 14 is the central control system circuit. The micro-processor has a built-in analog-to-digital converter (ADC) which can be used to detect the time of sun rise (beginning of daytime) or the time of sunset (beginning of night time) by measuring the voltage of PV. The ADC is also used to measure the battery voltage during charge. The current during discharge was measured by a $0.003 \Omega$ resistor connected to the MOSFET and used to calculate the current by Ohm's law. An operational amplifier was used to amplify the voltage signal of the $0.003 \Omega$ resistor for feedback to the ADC. The charge and discharge feedback control system can be realized when the battery voltage and the discharge current are measured by the ADC in PIC micro-processor.

\section{Long-term field test of solar-powered LED lighting systems}

Two stand-alone solar LED lighting systems were built and tested outdoor in the campus of National Taiwan University using the high-performance charge/discharge control technique

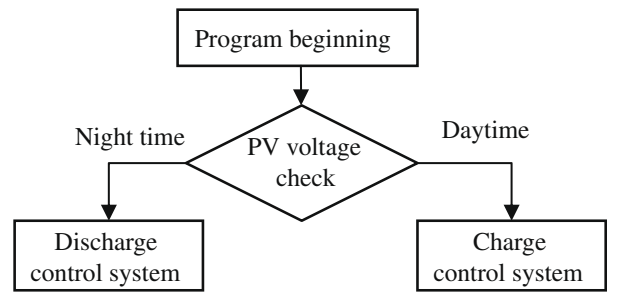

Fig. 13. The system control algorithm. described previously. The LED is turned on automatically at sunset when the sky is dark and turned off in the morning when the sky is bright. The open-circuit voltage of the PV module is used to detect the sunrise or sunset using a signal filter.

\subsection{W solar-powered LED lighting system}

This system using an $18 \mathrm{~W}$ LED luminaire, $80 \mathrm{Wp}$ PV module, a YUASA NP38-12 lead-acid battery, and a controller developed in the present study (Fig. 15). The long-term performance was monitored.

Figs. 16 and 17 show the recorded daily lighting hours in 2007 and 2008. The 2007 test data covers the spring and winter seasons

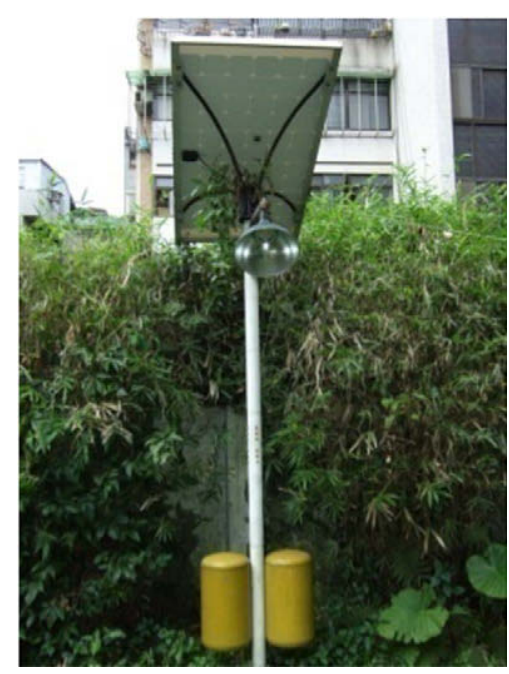

Fig. 15. $18 \mathrm{~W}$ solar-powered LED lighting system.

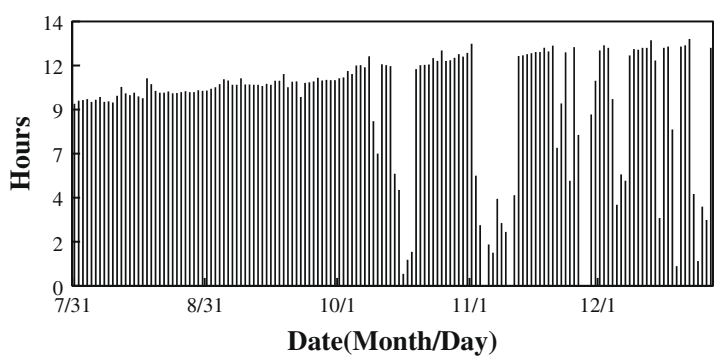

Fig. 16. Daily lighting hours of the $18 \mathrm{~W}$ solar-powered LED in 2007.

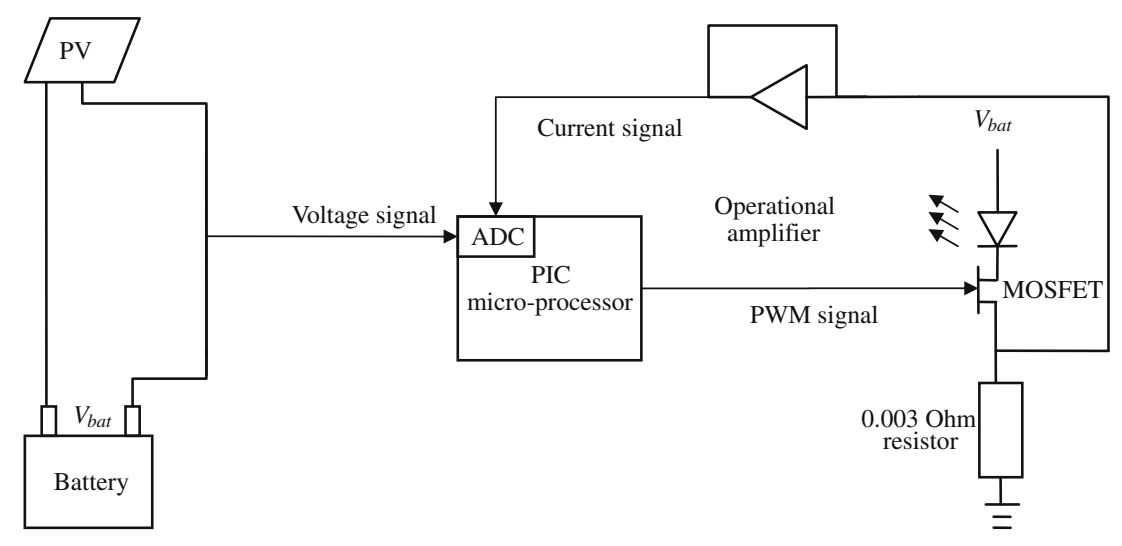

Fig. 14. The central control system circuit. 


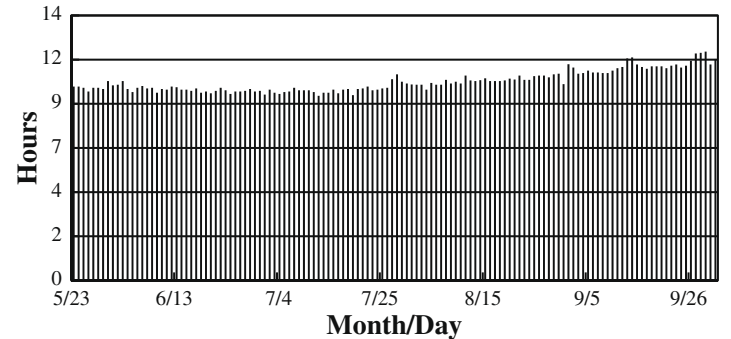

Fig. 17. Daily lighting hours of the $18 \mathrm{~W}$ solar-powered LED measured in 2008.

which have lower solar radiation. There are 172 recorded days and 28 days cannot provide all-night lighting. The total number of hours losing lighting is $270 \mathrm{~h}$ and the loss of load probability $(\operatorname{LLP})$ is $(270 / 1920) 100 \%=14.1 \%$. The 2008 test data are taken in summer. There are 132 recorded days and the system can provide all-night lighting every day with zero LLP.

\section{2. $100 \mathrm{~W}$ solar-powered LED lighting system}

The $100 \mathrm{~W}$ solar-powered LED lighting system is developed for highway lighting (Fig. 18) and consists of a 100 W LED luminaire, a $400 \mathrm{Wp}$ solar PV module, a $48 \mathrm{~V} 100 \mathrm{~A}$ h lead-acid battery, and a controller developed in the present study.

This system was installed on 2007/12/26. The data logger was installed on $2008 / 03 / 21$. Fig. 19 shows the lighting hours from $2008 / 03 / 21$ to $2008 / 11 / 19$.

There are no recorded data from $5 / 28$ to $6 / 9,7 / 1$ to $8 / 20$ and $10 /$ 2 to $10 / 21$ due to the failure of the data logger. For the 159 recorded days, only nine days do not provide all-night lighting. The loss of load probability LLP is $3.6 \%$ counted by lighting hours. This occurs in spring. No failure occurs so far for the $100 \mathrm{~W}$ solar-powered LED lighting system.

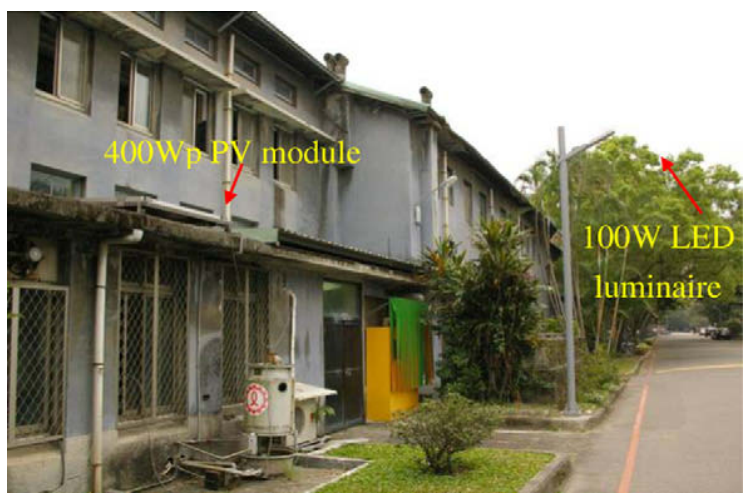

Fig. 18. $100 \mathrm{~W}$ solar-powered LED roadway lighting system.

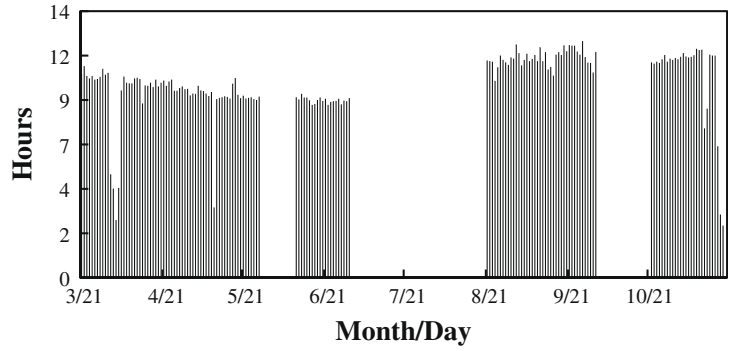

Fig. 19. Test results of $100 \mathrm{~W}$ solar-powered lighting system.

\section{3. $150 \mathrm{~W}$ solar-powered LED lighting system}

To show the application of the present technology for LED with higher power, a $150 \mathrm{~W}$ solar-powered LED lighting system is developed for test and comparison, in addition to the $100 \mathrm{~W}$ solar-powered LED lighting system. The system consists of a $150 \mathrm{~W}$ LED luminaire (Fig. 20), a $720 \mathrm{Wp}$ solar PV module (Fig. 21), a $48 \mathrm{~V}$ $100 \mathrm{~A} \mathrm{~h}$ lead-acid battery, and a controller developed in the present study.

Fig. 22 shows the lighting hours from 2009/01/07 to 2009/08/ 10. There are missing data from $3 / 10$ to $5 / 10$ due to the failure of the data logger. For the 152 recorded days, 114 days do not provide all-night lighting. The loss of load probability LLP is $46.8 \%$ calcu-

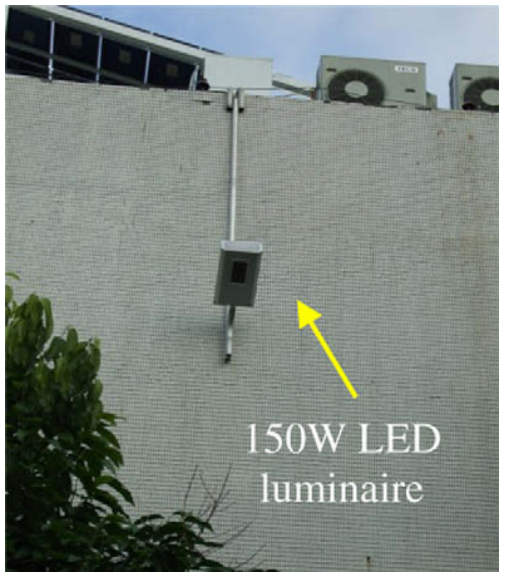

Fig. 20. $150 \mathrm{~W}$ LED in solar roadway lighting system.

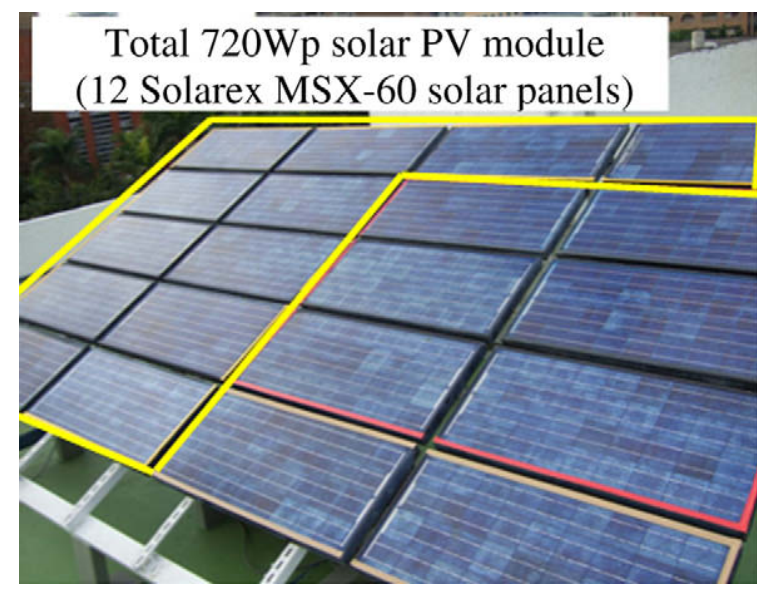

Fig. 21. Solar PV module used in $150 \mathrm{~W}$ roadway lighting system.

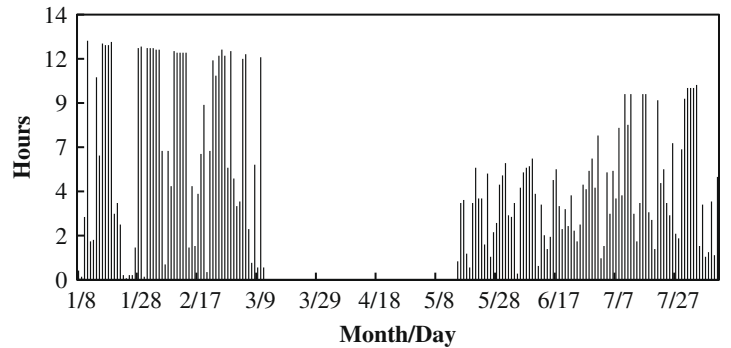

Fig. 22. Daily lighting hours at night of $150 \mathrm{~W}$ solar-powered LED (2009). 
lated by expected lighting hours. The high LLP is caused by the use of a lower battery capacity $100 \mathrm{~A} \mathrm{~h}$ which is the same as $100 \mathrm{~W}$ solar-powered LED lighting system. The $150 \mathrm{~W}$ system has been run from winter to summer and no failure occurs so far. The field test shows that the controller can be used for the $150 \mathrm{~W}$ solar-powered LED lighting system too. The LLP can be improved easily by using larger battery.

\section{Discussion and conclusions}

The present study developed a high-efficiency charge/discharge controller for stand-alone solar LED lighting system by incorporating an nMPPO (near-maximum-power-point-operation) design, a PWM battery charge control, and a PWM battery discharge control to drive the LED.

The near-maximum-power-point-operation (nMPPO) design of photovoltaic power generation system [5] can get rid of a maximum-power-point-tracking controller MPPT by just properly matching the PV module specification with the battery voltage in design to obtain a similar performance of MPPT. The additional cost, reliability, and energy loss of the MPPT is thus avoided.

A battery charge control system using PWM technique with feedback control is developed in the present study to charge the battery in full capacity. The daily outdoor experiment shows the battery capacity can be charged $9.7 \%$ more after the overcharge point.

For LED driven by PWM current directly from battery to eliminate the DC/DC conversion loss, a reliability test for the light decay of LED lamps was performed continuously for $15,800 \mathrm{~h}$. It has shown that the light decay of PWM-driven LED is the same as that of constant-current driven LED. The energy loss of the MOSFET in the PWM battery discharge control is less than 1\%. Further improvement is underway by using better MOSFET or new circuit design.

The conventional DC/DC converter circuit used in solar-powered system consists of capacitor, semiconductor (MOSFET), and inductor. The probability of failure of each component is $72 \%$, $24 \%$, and $3 \%$ respectively for capacitor, MOSFET and inductor, due to increase in equivalent series resistance (ESR), thermal stress cracks, and shorting windings respectively [12]. The present solar control system uses no DC/DC, only MOSFET is used for charging and discharging control.

The failure mode of the MOSFET is the thermal stress cracks. It can be reduced by adopting higher voltage system to reduce the charge/discharge current or using a better thermal management device to dissipate the heat of the MOSFET. Thus the system reliability can be increased by comparison to the use of conventional DC/DC converter.
Three solar-powered LED lighting systems $(18 \mathrm{~W}, 100 \mathrm{~W}$ and $150 \mathrm{~W}$ LED) were designed and built according to the developed technology. The long-term outdoor field test results have shown that the system performance is satisfactory with the control system developed in the present study. The loss of load probability for the $18 \mathrm{~W}$ solar LED system is $14.1 \%$ in winter and zero in summer. For the $100 \mathrm{~W}$ solar LED system, the loss of load probability is $3.6 \%$ in spring. The LLP of the $150 \mathrm{~W}$ solar LED system is much higher than other two systems and it can be reduced if the battery capacity is increased. The field test of the three solar-powered LED lighting systems is covering winter and summer conditions. No failure happened to the controller except the data logger. The long-term field tests show the controller developed in the present study has good stability in charging the battery and driving the LED luminaire.

\section{Acknowledgments}

This publication is based on the work supported in part by Award No. KUK-C1-014-12, made by King Abdullah University of Science and Technology (KAUST) and the Project No. 97-D0137-1 made by Energy Bureau, Ministry of Economic Affairs, Taiwan.

\section{References}

[1] Hadj Arab A, Chenlo F, Benghanem M. Loss-of-load probability of photovoltaic water pumping systems. Solar Energy 2004;76:713-23.

[2] Salameh Z, Taylor D. Step-up maximum power point tracker for photovoltaic arrays. Solar Energy 1990;44(1):57-61.

[3] Salameh Z, Dagher F, Lynch WA. Step-down maximum power point tracker for photovoltaic system. Solar Energy 1991;46(1):278-82.

[4] Huang BJ, Sun FS, Ho RW. Near-maximum-power-point-operation (nMPPO) design of photovoltaic power generation system. Solar Energy 2006;80:1003-20.

[5] Koutroulis E, Kalaitzakis K. Novel battery charging regulation system for photovoltaic applications. In: IEE proc-electr power appl, vol. 151 (2); March 2004.

[6] Huang BJ, Sun FS. Feasibility study of one axis three positions tracking solar PV with low concentration ratio reflector. Energy Convers Manage 2007; 48:1273-80.

[7] Huang BJ, Wu Min-Sheng, Huang HH, Chen JW. Economic analysis of solarpowered LED roadway lighting. In: Solar world congress 2007, September 1722; 2007. p. 466-70

[8] Barton Daniel L, Osinski Marek, Perlin Piotr, Eliseev Petr G, Lee Jinhyun. Singlequantum well InGaN green light emitting diode degradation under high electrical stress. Microelectron Reliab 1999;39:1219-27.

[9] Meneghini M, Morelli A, Pintus R, Meneghesso G, Vanzi M, Zanoni E. High brightness GaN LEDs degradation during dc and pulsed stress. Microelectron Reliab 2006;46:1720-4.

[10] Meneghini M, Trevisanello L, Podda S, Buso S, Spiazzi G, Meneghesso G, et al. Stability and performance evaluation of High Brightness Light Emitting Diodes under DC and pulsed bias conditions. In: SPIE, sixth international conference on solid state lighting, vol. 63370R; 2006. p. 63370R-1.

[11] YUASA. NP 38-12 lead-acid battery technical datasheet; March 09.

[12] Military handbook 217F. Reliability prediction of electronic equipment; 1995. 